\title{
Sera Koşullarında Farklı Sulama Suyu Miktarı ve Solucan Gübresi Dozlarının Fesleğen (Ocimum basilicum L.) Bitkisinin Bazı Vejetatif Özelliklerine Etkileri*
}

\author{
Muhtasım Toprak ${ }^{1}$, Ulaş Şenyiğit ${ }^{2 * \dagger}$ \\ ${ }^{1}$ T.C. Tarım ve Orman Bakanlığı, Sütçüler İlçe Tarım ve Orman Müdürlüğ̈̈, Sütçüler, Isparta, Türkiye, (ORCID: 0000-0001-6993-327X) muhtasimtoprak@gmail.com \\ ${ }^{2 *}$ Isparta Uygulamalı Bilimler Üniversitesi, Ziraat Fakültesi, Tarımsal Yapılar ve Sulama Bölümü, Isparta, Türkiye (ORCID: 0000-0002-4864-0790), \\ ulassenyigit@isparta.edu.tr
}

(First received 8 November 2021 and in final form 12 December 2021)

(DOI: 10.31590/ejosat.1020633)

ATIF/REFERENCE: Toprak, M. \& Şenyiğit, U. (2021). Sera Koşullarında Farklı Sulama Suyu Miktarı ve Solucan Gübresi Dozlarının Fesleğen (Ocimum basilicum L.) Bitkisinin Bazı Vejetatif Özelliklerine Etkileri. Avrupa Bilim ve Teknoloji Dergisi, (31), 629-633.

$\ddot{O} \mathbf{z}$

$\mathrm{Bu}$ araştırma, farklı sulama suyu miktarı ve solucan gübresi dozlarının fesleğen bitkisinin (Ocimum basilicum L.) vejetatif özelliklerinden bitki boyu, boğum sayısı ve bitki gövde çapına etkilerini belirlemek amacıyla Isparta ili, Sütçüler ilçesi, Çandır köyünde kurulan plastik serada yer alan saksılarda yürütülmüştür. Çalışmada, farklı solucan gübresi dozları $\left(\mathrm{G}_{0}\right.$; solucan gübresi kullanılmayan, $\mathrm{G}_{1} ; 3.5 \mathrm{~g} / \mathrm{saks1}$ ve $\left.\mathrm{G}_{2} ; 7 \mathrm{~g} / \mathrm{saks1}\right)$ ile farkl1 sulama suyu miktarlarının ( $\mathrm{S}_{100}$ : tam sulama, $\mathrm{S}_{75}, \mathrm{~S}_{50}, \mathrm{~S}_{25}$ : k1sitl1 sulama ve $\mathrm{S}_{0}$ : susuz) uygulandığı konular yer almıştır.

En düşük sulama suyu miktarı $\mathrm{S}_{0}$ konularına $27.66 \mathrm{~mm}$ ile uygulanırken, en yüksek $\mathrm{S}_{100} \mathrm{G}_{0}$ konusuna $1699.56 \mathrm{~mm}$ olarak uygulanmıştır. Çalışmada, en yüksek bitki boyu, $\mathrm{S}_{75} \mathrm{G}_{2}$ konusundan $(34.02 \mathrm{~cm})$ elde edilirken, en düşük bitki boyu ise $\mathrm{S}_{0} \mathrm{G}_{1}$ konusundan $(12.44 \mathrm{~cm})$ elde edilmiş̧tir. Bitki gövdesindeki boğum sayısı en fazla 5.60 adet/bitki ile $\mathrm{S}_{100} \mathrm{G}_{2}$ konusundan, en az ise 2.76 adet/bitki ile $\mathrm{S}_{0} \mathrm{G}_{0}$ ve $\mathrm{S}_{0} \mathrm{G}_{1}$ konularından gözlenmiştir. Ölçülen bitki gövde çapı değerleri $6.15 \mathrm{~mm}$ ile $\left(\mathrm{S}_{100} \mathrm{G}_{1}\right) 3.29 \mathrm{~mm}\left(\mathrm{~S}_{0} \mathrm{G}_{0}\right)$ arasında değişmiştir. Elde edilen sonuçlara göre bitki boyu, boğum sayısı ve bitki gövde çapı değerleri, farklı sulama konuları arasında istatistiksel olarak önemli bulunurken $(\mathrm{p}<0.01)$, solucan gübre dozu konuları arasında önemsiz bulunmuştur.

Anahtar Kelimeler: Fesleğen, Solucan Gübresi, Sulama Suyu, Bitki Boyu, Boğum Sayısı, Gövde Çap1

\section{The Effects of Different Irrigation Water Amounts and Vermicompost Doses on Some of the Vegetative Paramaters of Basil (Ocimum basilicum L.) under Greenhouse Conditions}

\begin{abstract}
This study was carried out in pots with soil in a plastic greenhouse established in Isparta province, Sütçüler district, Çandır village in order to determine the effects of different vermicompost doses $\left(\mathrm{G}_{0}\right.$; no vermicompost, $\mathrm{G}_{1} ; 3.5 \mathrm{~g} /$ pot and $\mathrm{G}_{2} ; 7 \mathrm{~g} /$ pot $)$ and irrigation water amounts ( $\mathrm{S}_{100}$ : full irrigation, $\mathrm{S}_{75}, \mathrm{~S}_{50}, \mathrm{~S}_{25}$ : deficit irrigation and $\mathrm{S} 0$ : no irrigation) on vegetative parameters such as plant height, number of nodes and plant stem diameter of basil (Ocimum basilicum L.).

While the maximum irrigation water amount were applied to $\mathrm{S}_{100} \mathrm{G}_{0}$ treatment as $1699.56 \mathrm{~mm}$, the minimum was applied to $\mathrm{S}_{0}$ treatments as $27.66 \mathrm{~mm}$. The highest and lowest plant height values related to the treatments were determined from $\mathrm{S}_{75} \mathrm{G}_{2}(34.02 \mathrm{~cm})$ and $\mathrm{S}_{0} \mathrm{G}_{1}$ $(12.44 \mathrm{~cm})$, respectively. The maximum number of nodes in the plant stem was observed from $\mathrm{S}_{100} \mathrm{G}_{2}$ with 5.60 units/plant, and the least from $\mathrm{S}_{0} \mathrm{G}_{0}$ and $\mathrm{S}_{0} \mathrm{G}_{1}$ treatments with 2.76 units/plant. The measured plant stem diameter values ranged from $6.15 \mathrm{~mm}\left(\mathrm{~S}_{100} \mathrm{G}_{1}\right)$ to 3.29 $\mathrm{mm}\left(\mathrm{S}_{0} \mathrm{G}_{0}\right)$. According to the results obtained, plant height, number of nodes and plant stem diameter values were found to be statistically significant among different irrigation treatments $(\mathrm{p}<0.01)$, while was found to be insignificant among vermicompost doses treatments.
\end{abstract}

Keywords: Basil, Vermicompost, Irrigation Water, Plant Height, Node Number, Stem Diameter

\footnotetext{
* Bu makalede kullanılan veriler YÖK Ulusal Tez Merkezinde yer alan 672114 nolu Yüksek Lisans tezinden alınmıştır. Sözlü sunum olarak ICAAW 2021 Kongresinde sunulmuştur.

$\dagger$ Corresponding Author: ulassenyigit@isparta.edu.tr
} 


\section{Giriş}

Türkiye, tıbbi ve aromatik bitkiler bakımından, dünyanın zengin ülkelerinden biridir. Bu bitkiler içerisinde önemli bir yere sahip olan fesleğen (Ocinum basilicum L.) Labiatae familyasının, Ocimoideae alt familyasından Ocimum cinsi, tek yıllık otsu bir bitki türü olup birçok çeşide sahiptir (Balyan ve Pushpangadan, 1988).

Türkiye nüfusunun tahminlere göre 2050 yılında 110 milyon olacağ1 beklenmektedir (TÜİK, 2020). Bu nüfusun ihtiyaç duyduğu gıda ile su gereksinimlerini karşılamak için hem su hem de toprak kaynaklarının akılcı kullanılıp, çok iyi korunması gerekmektedir. Sulama, diğer tarımsal girdilerin etkinliğini ve verimliliğini artıran, tarımsal üretimde karlılığı ve ekonomiyi sağlayan çok yönlü uygulamalardan birisidir (Korukçu, 1992). Kisitlı su kaynakları ile bitkinin tam su gereksiniminden daha az su uygulanması olarak tanımlanan kısitlı sulama, sulama suyu kullanımının azaltılması ve su kullanım verimliliğini arttırma hedefine ulaşmak için önemli potansiyele sahip bir sulama stratejisidir. Bitki veriminde önemli kayılara neden olmadan, bitkinin suya duyarlılığına göre tüm yetiştirme sezonu boyunca veya farklı gelişim dönemlerinde belirli oranlarda su tasarrufu sağlayan kontrollü kısıtlı sulamanın, su kullanımını azaltarak ekonomik geliri arttırdığı bildirilmiştir (Fereres ve Sariano, 2007; Keten ve Değirmenci, 2020; Bekele ve Tilahun, 2007; Geerts ve Raes, 2009).

Bitkisel üretimde bir diğer önemli girdi olan bitki besin ihtiyacının organik kaynak ile kısmen karşılandığı vermikompost uygulamaları, bitkisel üretimde kalite ve verim artışı ile birlikte yüksek su tutma kapasitesi, katyon değişim kapasitesi, gözeneklilik oranı ile havalanma ve mikrobial aktivite sağlayarak toprağın fiziksel ve kimyasal özelliklerine de olumlu katkılar sağlamaktadır (Bossuyt vd., 2005; Tejada ve González, 2009; Ateş ve Coşkan, 2016; Bellitürk, 2018).

$\mathrm{Bu}$ araştırma, farklı sulama suyu miktarı ve solucan gübresi dozlarının fesleğen (Ocimum basilicum L.) bitkisinin bazı vejetatif gelişim parametrelerine etkilerinin belirlenmesi amac1yla yürütülmüşstür.

\section{Materyal ve Metot}

Çalışma, Isparta İli, Sütçüler İlçesi, Çandır Köyünde (37² $26^{\prime}$ $13 " \mathrm{~K}$ enlemi ile $30^{\circ} 53^{\prime} 40^{\prime \prime} \mathrm{D}$ boylami arasinda, denizden yüksekliği $280 \mathrm{~m}$ ) yer alan taban alanı $540 \mathrm{~m}^{2}$, yüksekliği ise $4 \mathrm{~m}$ olan 1sıtmasız plastik örtülü serada 2020 yılı Nisan-Ağustos dönemleri arasında yürütülmüştür. Üst çap1 $21 \mathrm{~cm}$, yüksekliği 19 $\mathrm{cm}$ ve yüzey alanı $346 \mathrm{~cm}^{2}$ olan saksılarda, yetiştirme ortamı olarak Tınlı bünyeye sahip, hacim ağırlığ $0.97 \mathrm{~g} / \mathrm{cm}^{3}$ ve saksı kapasitesi $120.6 \mathrm{~mm}$ olan toprak kullanılmıştır. Denemenin yürütüldüğü bölge, Akdeniz iklimine yakın bir iklim rejimine sahip olup, Sütçüler ilçesinin ortalama sıcaklığg $14.1^{\circ} \mathrm{C}$, ortalama bağıl nemi \%58.1 ve ortalama toplam yağış miktarı ise $836 \mathrm{~mm}$ 'dir (MGM, 2020). Deneme serasında, vejetasyon dönemi boyunca en düşük ve en yüksek sıcaklık değerleri aylık ortalama 7.3 ile 43.1 ${ }^{\circ} \mathrm{C}$ arasında değişirken oransal nem değerleri $\% 10$ ile $\% 90$ arasında değişmiştir. Uygulanan sulama suyunun elektriksel iletkenliği $0.355 \mathrm{mmhos} / \mathrm{cm}, \mathrm{pH}$ '1 7.67 ve kalite sınıfı $\mathrm{C}_{2} \mathrm{~S}_{1}$ 'dir. Çalışmada, Fesleğen (Ocimum basilicum L) türünün tek yıllık Genovese çeşidi kullanılmıştır.
Deneme konularına göre solucan gübre dozları toprak ile iyice karıştırıldıktan sonra saksılara konulmuş ve her saksıya 3 adet fide dikilmiştir. Denemede toplam $52.5 \mathrm{~g} / \mathrm{saks}$ MAP (Mono Amonyum Fosfat), $120 \mathrm{~g} / \mathrm{saks} 1\left(\mathrm{NH}_{4}\right)_{2} \mathrm{SO}_{4}$ (Amonyum Sülfat) ve $123 \mathrm{~g} / \mathrm{saks} 1 \mathrm{~K}_{2} \mathrm{SO}_{4}$ (Potasyum Sülfat) uygulanmıştır.

Farklı solucan gübre dozlarının oluşturulmasında $0 \mathrm{~g} / \mathrm{saks}$ $\left(\mathrm{G}_{0}\right), 3.5 \mathrm{~g} / \mathrm{saks} 1\left(\mathrm{G}_{1}\right)$ ve $7 \mathrm{~g} / \mathrm{saks} 1\left(\mathrm{G}_{2}\right)$ oranları kullanılmıştır. Her solucan gübre dozu için eksilen toprak nemini saksı kapasitesine çıkarmak için verilecek suyun tamamının uygulandığı $\left(\mathrm{S}_{100}\right)$ konu baz alınarak bu su miktarının \% 25, \% 50 ve \% 75'nin $\left(\mathrm{S}_{25}, \mathrm{~S}_{50}\right.$, $\mathrm{S}_{75}$ : kısıtlı sulama) uygulandığı sulama konuları ve susuz konu $\left(\mathrm{S}_{0}\right)$ yer almıştır.

Denemede, sulama konularına başlamadan önce tüm konular saksı kapasitesine getirilmiş ve ardından konulara uygulanan sulama suyu miktarının belirlenmesi için saksılar periyodik olarak tartılarak toprak nem düzeyleri gravimetrik yolla izlenmiştir. Her bir gübre dozu için sulama konularına uygulanacak sulama suyu miktarları ağırlık esasına göre Eşitlik 1 yardımıyla belirlenmiştir (Şenyiğit vd., 2021).

\section{$\mathrm{S}=(\mathrm{SK}-\mathrm{MN}) \times \mathrm{Sd}$}

Eşitlikte, S, sulama suyu (ml), SK, saksı kapasitesi (g), MN, sulama öncesi mevcut nem (g), Sd, sulama düzeyidir (\%).

Denemede bitkilerin boyları, toprak yüzeyinden bitkinin en uç noktasına kadar cetvel ile, bitki gövde çapları kumpas yardımıyla ölçülürken, boğum sayıları ise gözlem yoluyla sayılarak tespit edilmiş ve saksıda yer alan üç bitkinin ortalaması alınmıştır.

Deneme, tesadüf parsellerinde faktöriyel düzen deneme desenine göre 3 yinelemeli olarak yürütülmüş ve istatistiksel analizler için Minitab ${ }^{\circledR} 19$ istatistik programı ve konular arasındaki farklılıkları belirlemek için Tukey Testi uygulanmıştır.

\section{Araştırma Sonuçları ve Tartışma}

\subsection{Sulama Suyu}

Sulama suyu miktarı, en yüksek $\mathrm{S}_{100} \mathrm{G}_{0}$ konusuna toplam $1699.56 \mathrm{~mm}$, en düşük ise $\mathrm{S}_{0}$ konularına $27.66 \mathrm{~mm}$ (can suyu) olarak uygulanmıştır (Tablo 3.1). $\mathrm{G}_{1}$ ve $\mathrm{G}_{2}$ konularında uygulanan sulama suyu miktarları genel olarak solucan gübresi uygulanmayan $\mathrm{G}_{0}$ konularına göre daha düşük olurken, tam sulama konularında sırasıyla yaklaşık $\% 2.36$ ve $\% 4.57$ oranlarında daha az gerçekleşmiştir. Uygulanan sulama suyu miktarı Ekren vd. (2012) ve Borivoj vd. (2017) göre daha yüksek olduğu belirlenmiştir. Uygulanan sulama suyu miktarının değinilen çalışmalara göre daha yüksek olması, çalışmanın sera koşullarında yürütülmesi, vejetasyon süresinin uzun olması ve bölgenin iklim özellikleri ile açıklanabilir.

\subsection{Bitki Boyu}

Çalışmada en yükssek bitki boyu, $\mathrm{S}_{75} \mathrm{G}_{2}$ konusundan 34.02 $\mathrm{cm}$, en düşük bitki boyu ise $\mathrm{S}_{0} \mathrm{G}_{1}$ konusundan $12.44 \mathrm{~cm}$ olarak elde edilmiştir (Tablo 3.2). Elde edilen bitki boyu verilerine göre sulama düzeyleri konuları arasında istatistiksel olarak önemli düzeyde farklılıklar belirlenmiştir $(\mathrm{p}<0.01)$. Aynı sulama düzeyindeki solucan gübre dozu konuları arasında elde edilen bitki boyu değerleri ise istatistiksel olarak önemli bulunmamıştır. Genel olarak, bitki boyunun solucan gübre dozu ve sulama suyu düzeyinin artmasıyla Şenyiğit vd. (2021) tarafindan cam sera koşullarında yapılan çalışmayla benzer olarak arttığı 
gözlenmiştir. $S_{100}$ ve $S_{75}$ sulama düzeylerinde elde edilen bitki boyu en üst sinıfta yer alırken onu sirasıyla, $S_{50}, S_{25}$ ve $S_{0}$ konuları takip etmiştir. Çalışmada tam sulama konularında elde edilen bitki boyu değerleri, Telci (2005), Moghaddam (2010), Karık vd. (2014), Cabar (2016), Köse (2017), Karaca vd. (2017), Yaldız vd.
(2017 tarafından su kısıtı olmayan çalışmalardan yapılmış sonuçlar ile benzerlik gösterirken, Ekren vd. (2012), Sifola ve Barbieri (2006), Omer vd. (2008), Kulan (2013) ve Sönmez vd. (2019) tarafından elde edilen değerlerden daha düşük çıkmıştır.

Tablo 3.1. Konulara ilişkin sulama suyu miktarl (mm)

\begin{tabular}{|c|c|c|c|c|c|}
\hline Konular & $\mathrm{S}_{0}$ & $\mathrm{~S}_{25}$ & $\mathrm{~S}_{50}$ & $\mathrm{~S}_{75}$ & $\mathrm{~S}_{100}$ \\
\hline $\mathrm{G}_{0}$ & 27.66 & 445.63 & 863.61 & 1281.58 & 1699.56 \\
\hline $\mathrm{G}_{1}$ & 27.66 & 435.46 & 843.25 & 1251.05 & 1658.85 \\
\hline $\mathrm{G}_{2}$ & 27.66 & 425.91 & 824.15 & 122.40 & 1620.64 \\
\hline
\end{tabular}

Tablo 3.2. Deneme konularına ilișkin bitki boyu değerleri (cm)

\begin{tabular}{|c|c|c|c|c|c|c|}
\hline Konular & $\mathrm{S}_{0}$ & $\mathrm{~S}_{25}$ & $\mathrm{~S}_{50}$ & $\mathrm{~S}_{75}$ & $\mathrm{~S}_{100}$ & Ortalama \\
\hline $\mathrm{G}_{0}$ & $12.62 \pm 0.92$ & $17.71 \pm 0.45$ & $25.36 \pm 0.84$ & $31.42 \pm 2.08$ & $31.89 \pm 2.58$ & $23.80 \pm 2.12$ \\
\hline $\mathrm{G}_{1}$ & $12.44 \pm 0.58$ & $17.78 \pm 0.52$ & $26.56 \pm 1.15$ & $31.78 \pm 1.59$ & $33.20 \pm 1.35$ & $24.35 \pm 2.19$ \\
\hline $\mathrm{G}_{2}$ & $12.58 \pm 0.27$ & $19.62 \pm 0.21$ & $28.02 \pm 1.60$ & $34.02 \pm 1.40$ & $33.00 \pm 0.90$ & $25.45 \pm 2.23$ \\
\hline Ortalama & $12.55 \pm 0.33 \mathrm{D}$ & $18.37 \pm 0.38 \mathrm{C}$ & $26.64 \pm 0.73 \mathrm{~B}$ & $32.41 \pm 0.95 \mathrm{~A}$ & $32.70 \pm 0.90 \mathrm{~A}$ & \\
\hline
\end{tabular}

\subsection{Gövdedeki Boğum Sayısı}

Aynı sulama düzeyindeki farklı solucan gübre dozu konuları arasında elde edilen boğum sayısı değerleri istatistiksel olarak önemli bulunmazken ( $\mathrm{p}<0.01)$, en yüksek boğum sayısı değerleri istatistiksel olarak aynı sinıfta yer alan $S_{100}$ ve $S_{75}$ sulama konularında elde edilmiş ve diğer konulardan elde edilen boğum sayısı değerleri sulama suyu düzeyi ile orantılı olarak azalmıştır (Tablo 3.3). Çalışmada rakamsal olarak bitki gövdesindeki en fazla boğum sayıs 5.60 adet/bitki ile $\mathrm{S}_{100} \mathrm{G}_{2}$ konusundan, en az boğum sayısı ise 2.76 adet/bitki ile $S_{0} G_{0}$ ve $S_{0} G_{1}$ konularından elde edilmiştir. En yüksek bitki gövde çap1 $6.15 \mathrm{~mm}$ ile $\mathrm{S}_{100} \mathrm{G}_{1}$ konusundan, en düşük bitki gövde çap1 ise $3.29 \mathrm{~mm}$ ile $\mathrm{S}_{0} \mathrm{G}_{0}$ konusundan elde edilmiştir (Tablo 3.4). Bitki çapı değerleri farklı sulama suyu düzeyi konuları arasında istatistiksel olarak önemli bulunurken, en yüksek bitki çapı değerleri tam sulama konularında saptanmış ve diğer kısıtlı ve susuz konularda ise uygulanan sulama suyu miktarına göre azalmıştır $(\mathrm{p}<0.01)$.

\subsection{Bitki Gövde Çapı}

Çalışmada rakamsal olarak en yüksek bitki gövde çap1 6.15 $\mathrm{mm}$ ile $\mathrm{S}_{100} \mathrm{G}_{1}$ konusundan, en düşük bitki gövde çapı ise $3.29 \mathrm{~mm}$ ile $\mathrm{S}_{0} \mathrm{G}_{0}$ konusundan elde edilmiştir (Tablo 3.4). Bitki çap değerleri farklı sulama suyu düzeyi konuları arasında istatistiksel olarak önemli bulunurken, en yüksek bitki çapı değerleri tam sulama konularında saptanmış ve diğer kısıtlı ve susuz konularda ise uygulanan sulama suyu miktarına göre azalmıştır $(\mathrm{p}<0.01)$.

Tablo 3.3. Deneme konularına ilişkin gövdedeki boğum sayısı değerleri (adet/bitki)

\begin{tabular}{|c|c|c|c|c|c|c|}
\hline Konular & $\mathrm{S}_{0}$ & $\mathrm{~S}_{25}$ & $\mathrm{~S}_{50}$ & $\mathrm{~S}_{75}$ & $\mathrm{~S}_{100}$ & Ortalama \\
\hline $\mathrm{G}_{0}$ & $2.76 \pm 0.24$ & $3.38 \pm 0.18$ & $4.51 \pm 0.17$ & $5.40 \pm 0.21$ & $5.58 \pm 0.26$ & $4.32 \pm 0.31$ \\
\hline $\mathrm{G}_{1}$ & $2.76 \pm 0.24$ & $3.62 \pm 0.23$ & $4.80 \pm 0.10$ & $5.18 \pm 0.06$ & $5.58 \pm 0.08$ & $4.39 \pm 0.29$ \\
\hline $\mathrm{G}_{2}$ & $2.84 \pm 0.18$ & $4.00 \pm 0.20$ & $4.84 \pm 0.14$ & $5.42 \pm 0.18$ & $5.60 \pm 0.19$ & $4.54 \pm 0.28$ \\
\hline Ortalama & $2.79 \pm 0.11 \mathrm{D}$ & $3.67 \pm 0.14 \mathrm{C}$ & $4.72 \pm 0.09 \mathrm{~B}$ & $5.33 \pm 0.09 \mathrm{~A}$ & $5.59 \pm 0.10 \mathrm{~A}$ & \\
\hline
\end{tabular}


Tablo 3.4. Deneme konularına ilişkin bitki gövde çapı değerleri (mm)

\begin{tabular}{|c|c|c|c|c|c|c|}
\hline Konular & $\mathrm{S}_{0}$ & $\mathrm{~S}_{25}$ & $\mathrm{~S}_{50}$ & $\mathrm{~S}_{75}$ & $\mathrm{~S}_{100}$ & Ortalama \\
\hline $\mathrm{G}_{0}$ & $3.29 \pm 0.01$ & $4.68 \pm 0.12$ & $5.21 \pm 0.12$ & $5.45 \pm 0.09$ & $6.10 \pm 0.04$ & $4.95 \pm 0.26$ \\
\hline $\mathrm{G}_{1}$ & $3.50 \pm 0.12$ & $4.53 \pm 0.12$ & $5.07 \pm 0.15$ & $5.63 \pm 0.02$ & $6.15 \pm 0.17$ & $4.97 \pm 0.25$ \\
\hline $\mathrm{G}_{2}$ & $3.49 \pm 0.03$ & $4.47 \pm 0.07$ & $5.10 \pm 0.07$ & $5.87 \pm 0.17$ & $6.12 \pm 0.16$ & $5.01 \pm 0.26$ \\
\hline Ortalama & $3.43 \pm 0.05 \mathrm{E}$ & $4.56 \pm 0.06 \mathrm{D}$ & $5.12 \pm 0.06 \mathrm{C}$ & $5.65 \pm 0.08 \mathrm{~B}$ & $6.13 \pm 0.07 \mathrm{~A}$ & \\
\hline
\end{tabular}

\section{Sonuç}

Sera koşullarında yapılan fesleğen yetiştiriciliğinde, vejetatif gelişim parametreleri bakımından iyi sonuçların eldesi için sulamanın kaçınılmaz olduğu ortaya çıkmıştır. Elde edilen sonuçlara göre, gövde çapı değerleri dışında diğer vejetatif özellikler bakımından en yüksek değerlerin elde edildiği tam sulama konusu $\left(\mathrm{S}_{100}\right)$ ile \%25'lik su tasarrufunun gerçekleştiği $\mathrm{S}_{75}$ su kısıtı konusu istatiksel olarak aynı sınıfta yer almıştır. Bunun yanı sıra, her ne kadar gübre dozları arasında istatistiksel fark olmasa da vegetatif özellikler bakımından hem rakamsal olarak olumlu sonuç vermiş olması hem de daha az sulama suyunun kullanılmış olmasından dolayı çalışmada uygulanan en düşük solucan gübresi dozu olan $\mathrm{G}_{1}$ (3.5 g/saks1) konusunun birlikte uygulandığ $\mathrm{S}_{75} \mathrm{G}_{1}$ uygulaması sera koşullarında saksılarda yapılacak fesleğen yetiştiriciliği için önerilebilir.

\section{Kaynakça}

Ateş, N. \& Coşkan, A. (2016). Toprak Solucanı, Organik ve Mineral Gübreli Koşullarda Mısır Bitkisi Performansını Artırdı. Çukurova Tarım ve Gıda Bilimleri Dergisi, 31: 3949.

Balyan, S. S. \& Pushpangadan, P. (1988). A study on the Taxonomical Status and Geographic Distribution of the Genus Ocimum. The Pafai Journal, 10(2), 13-19.

Bekele, S. \& Tilahun, K. (2007). Regulated deficit irrigation scheduling of onion in a semiarid region of Ethiopia. Agricultural Water Management. 89, 148-52.

Bellitürk, K. (2018). Vermicomposting in Turkey: Challenges and Opportunities in Future. Eurasian Journal of Forest Science, 6 (4): 32-41.

Borivoj, P., Dušan A., Livija, M. \& Ksenija, M. (2017). Effect of Drip lrrigation on Yield, Evapotranspiration and Water Use Efficiency of Sweet Basil (Ocimum basilicum L.). Ratarstvo i Povrtarstvo, 54(3): 124-129. https://doi:10.5937/ratpov54-14808

Bossuyt, H., Six, J. \& Hendrix, P. F. (2005). Protection of Soil Carbon By Microaggregates within Earthworm Casts. Soil Biol. Biochem, 37: 251-258.

Cabar, B. S. (2016). Farklı Fesleğen (Ocimum basilicum L. ) Hatlarının Trakya Koşullarında Verim ve Kalite İle İlgili Bazı Özelliklerinin Belirlenmesi (Yüksek Lisans Tezi, Namık Kemal Üniversitesi, Fen Bilimleri Enstitüsü)

Ekren, S., Sönmez, Ç., Özçakal, E., Kurttaş, Y. S. K., Bayram, E. \& Gürgülü, H. (2012). The Effect of Different Irrigation Water Levels on Yield and Quality Characteristics of Purple Basil (Ocimum basilicum L.). Agricultural Water Management, 109, 155-161.

https://doi.org/10.1016/j.agwat.2012.03.004
Fereres, E. \& Soriano, M. A. (2007). Deficit irrigation for reducing agricultural water use. Journal of Experimental Botany, 58(2), 147-159.

Geerts, S. \& Raes, D. (2009). Deficit irrigation as an on-farm strategy to maximize crop water productivity in dry areas. Agricultural Water Management. 96, 1275- 1284.

Karaca, M., Kara, Ş. M. \& Özcan, M. M. (2017). Bazı Fesleğen (Ocimum basilicum L.) Popülasyonlarının Herba Verimi ve Uçucu Yağ Oranının Belirlenmesi. Ordu Üniversitesi Bilim ve Teknoloji Dergisi, 7(2), 160-169.

Karık, Ü., Çicek, F., Oğur, E., Çınar, O. \& Birol, B. (2014). Menemen Ekolojik Koşullarında Bazı Ticari ve Yerel Fesleğen (Ocimum Basilicum L.) Çeşitlerinin Morfolojik, Verim ve Kalite Özelliklerinin Belirlenmesi. Anadolu Ege Tarımsal Araştırma Enstitüsü Dergisi, 24 (2), 10 - 20.

Keten, M. \& Değirmenci, H. (2020). Farklı Sulama Seviyeleri Altında Yetiştirilen İkinci Ürün Silajlık Mısır ve Sorgum Bitkilerinin Yaprak Su Potansiyellerinin Karşılaştırılması. ISPEC Journal of Agricultural Sciences, 4(4), 865-874. https://doi.org/10.46291/ISPECJASv ol4iss4pp863-872

Korukçu, A. (1992). Sulamadaki Gelişmelerin Türkiye'ye Etkisi. Ankara, Toprak Su Araştırma Enstitüsü Yayınları.

Köse, İ. (2017). Bitki Sıklığının Fesleğende (Ocimum Basilicum L.) Herba Verimi ve Uçucu Yağ İçeriği Üzerine Etkisi (Yüksek Lisans Tezi, Ordu Üniversitesi, Fen Bilimleri Enstitüsü)

Kulan, E. G. (2013). Eskişehir Koşullarında Yetiştirilen Reyhan (Ocimum basilicum) Bitkisinin Bazı Bitkisel Özelliklerin ve Diurnal Varyabilitesinin Belirlenmesi (Yüksek Lisans Tezi, Eskişehir Osmangazi Üniversitesi, Fen Bilimleri Enstitüsü)

Meteroloji Genel Müdürlüğü (MGM), http://www.mgm.gov.tr/ (Son Erişim Tarihi: 07.05.2020)

Moghaddam, A. M. D. (2010). Fesleğen (Ocimum basilicum L.)' de Farklı Bitki Sıklığı ve Azot Dozlarının Verim, Verim Ögeleri, Uçucu Yağ Oranı ve Bileşenler Üzerine Etkileri (Doktora Tezi, Ankara Üniversitesi, Fen Bilimleri Enstitüsü)

Omer, E. A., Said-Al Ahl, H. A. H. \& Hendawy, S. F. (2008). Production, Chemical Composition and Volatileoil of Different Basil Species/Varieties Cultivated Under Egyptian Soil Salinity Conditions. Research Journal of Agriculture and Biological Sciences, 4(4), 293-300.

Sifola, M. I, , M. \& Barbieri, G. (2006). Growth, Yieldand Essential Oil Content of Three Cultivars of Basil Grown Under Different Levels of Nitrogen in The Field. Scientia Horticulturae, 108, 408-413. https://doi.org/10.1016/j.scienta.2006.02.002

Sönmez, Ç., Soysal, A. Ö. Ş., Yıldırım, A., Berberoğlu, F. \& Bayram, E. (2019). Farklı Biçim Zamanlarının Yeşil ve Mor Fesleğen (Ocimum basilicum L.) Tiplerinde Bazı Verim ve 
Kalite Özellikleri Üzerine Etkisi. Anadolu Ege Tarımsal Araştırma Enstitüsü Dergisi, 29(1): 39-49.

https://doi.org/10.18615/anadolu.568803

Şenyiğit, U., Toprak, M. \& Çoşkan, A. (2021). Farklı Sulama Suyu

Düzeyleri ve Vermikompost Dozlarının Cam Sera

Koşullarında Yetiştirilen Fesleğen (Ocimum basilicum L.)

Bitkisinin Su Tüketimi ve Verimine Etkileri. Türk Bilim ve

Mühendislik Dergisi, 3(1): 37-43.

https://dergipark.org.tr/tr/pub/tjse/issue/63054/923392

Tejada, M. \& González, J. L. (2009). Application of Two Vermicomposts on A Rice Crop: Effects on Soil Biological Properties and Rice Quality and Yield. Agronomy Journal, 101: 336-344.

https://doi.org/10.2134/agronj2008.0211

Telci, İ. (2005). Reyhan (Ocimum basilicum L.) Genotiplerinde Uygun Biçim Yüksekliklerinin Belirlenmesi. Gaziosmanpaşa Üniversitesi Ziraat Fakültesi Dergisi, 22 (2), 77-83.

Türkiye İstatistik Kurumu (TÜIK). Senaryolara göre nüfus, 20182080. http://www.tuik.gov.tr/PreTablo.do?alt_id=1027. (Erişim Tarihi: 19.05.2020)

Yaldız, G., Çamlıca M., Eratalar, S. A. \& Kulak, M. (2017). Farklı Dozda Kıbele Gübre Uygulamasının Fesleğen (Ocimum basilicum L.) Verimine Etkisi. Iğdır Üniversitesi Fen Bilimleri Enstitüsü Dergisi, 7(1), 363-370.

https://doi.org/10.21597/jist.2017127449 